\title{
AVALIAÇÃO DE DESEMPENHO NA GESTÃO DE RECURSOS HÍDRICOS: UMA REVISÃO DA LITERATURA ${ }^{1}$
}

\author{
PERFORMANCE MEASUREMENT IN WATER RESOURCES MANAGEMENT: A LITERATURE \\ REVIEW
}

Sara Meurer

Universidade Federal de Santa Catarina

sarameurer95@gmail.com

Sandra Rolim Ensslin

Universidade Federal de Santa Catarina

sensslin@gmail.com

Hans Michael Van Bellen

Universidade Federal de Santa Catarina

hans.michael@ufsc.br

\section{RESUMO}

Objetivo: Esta pesquisa objetiva mapear, na literatura científica internacional, características dos estudos que avaliem o desempenho da Gestão de Recursos Hídricos, de modo a contribuir para sua preservação no âmbito social, econômico e ambiental, para apontar oportunidades de futuras investigações.

Fundamento: A compreensão de que o uso inadequado da água pode reduzir sua disponibilidade atual e de futuras gerações tem impulsionado formação e fortalecimento de medidas organizacionais em busca da maneira mais adequada para enfrentar esse desafio. À vista disso, a Avaliação de Desempenho é ferramenta útil para examinar a racionalidade do Sistema de Gestão de Recursos Hídricos e realizar sua utilização sustentável e eficiente.

Método: Foi utilizado o instrumento de intervenção ProKnow-C para seleção e análise da literatura científica, formando um Portfólio Bibliográfico de 40 artigos.

Resultados: A área de gestão de recursos hídricos é considerada emergente; falta consenso dos pesquisadores sobre o que são medidas e métricas; poucos trabalhos apresentam um Sistema completo de Avaliação de Desempenho; existem falhas no nível métrico nos artigos analisados, destacando o uso excessivo de métricas quantitativas para avaliar o desempenho.

Contribuições: Ao identificar aspectos relevantes na literatura sobre o tema e ao expor oportunidades de pesquisas futuras, o artigo se destaca por suas contribuições teóricas. Ainda, auxilia gestores no desenvolvimento e monitoramento adequado de um Sistema de Avaliação de Desempe-

\footnotetext{
${ }^{1}$ Artigo recebido em: 20/02/2019. Revisado por pares em: 18/03/2019. Reformulado em: 20/04/2019. Recomendado para publicação em: 11/07/2019 por Adriana Fernandes de Vasconcelos (Editora Geral ). Publicado em: 02/09/2019. Organização responsável pelo periódico: UFPB
} 
nho dos Recursos Hídricos e, direta ou indiretamente, contribui para a sociedade como um todo, visto que incentiva a preservação de um recurso indispensável para a vida.

Palavras-chave: Gestão de Recursos Hídricos. Avaliação de Desempenho. Métricas. Revisão da Literatura. ProKnow-C.

\begin{abstract}
Objective: This research aims to map, in the international scientific literature, characteristics of the studies that measure the performance of Water Resources Management, in order to contribute to its preservation in social, economic and environmental aspects, to indicate opportunities for future research.
\end{abstract}

Background: The understanding that inadequate water usage can reduce its availability for current and future generations has promoted creation and strengthening of organizational measures looking for the most adequate way to face this challenge. From this point of view, Performance Measurement is a useful tool to examine the rationality of Water Resources Management System and achieve its sustainable and efficient use.

Method: The ProKnow-C instrument was used to select and analyse the scientific literature, creating a Bibliographic Portfolio of 40 articles.

Results: Area is considered emergent; there is a lack on researchers' consensus about what are the measures and metrics; few papers present a complete Performance Measurement System; there are metrical level failures in the analyzed articles, highlighting the excessive use of quantitative metrics to measure performance.

Contributions: Identifying literature relevant aspects about the theme and exposing future research opportunities, the article stands out for its theoretical contribution. Still, assists managers in adequate developing and monitoring of a Performance Management System of water resources and, directly or indirectly, contributes to society as a whole, since encourages the preservation of this indispensable resource for life.

Keywords: Water Resources Management. Performance Measurement. Metrics. Literature Review. ProKnow-C.

\title{
1 INTRODUÇÃO
}

A população mundial está crescendo rapidamente e estimativas mostram que, com as práticas atuais, o mundo enfrentará um déficit de $40 \%$ entre a demanda prevista e a disponibilidade de água até 2030 (The World Bank, 2017). Sabendo que a água sempre foi um bem essencial à vida humana e ao desenvolvimento econômico (Agência Nacional de Águas, 2013), o reconhecimento do papel da escassez de água e seca está levando a maioria dos países a colocar 'pressão' sobre a necessidade da gestão dos recursos hídricos (The World Bank, 2017).

A compreensão de que o uso inadequado da água pode reduzir sua disponibilidade atual e das futuras gerações tem impulsionado a formação e o fortalecimento de medidas organizacionais na busca da forma mais adequada para enfrentar esse desafio (Agência Nacional de Águas, 2013). Assim, é necessário que as políticas e as principais questões relacionadas à água sejam analisadas, avaliadas e ações tomadas dentro de um contexto social e de desenvolvimento geral (Biswas, 2004). Caso contrário, o papel significativo que a água desempenha no desenvolvimento social e na sobrevivência da humanidade (Ren et al., 2013), como melhoria do padrão e da qualidade de vida das pessoas, alívio da pobreza, distribuição de renda regional e equitativa e conservação ambiental, não poderá ser alcançado (Biswas, 2004). 
Para que o papel desempenhado pela água não se desvaneça, a Gestão de Recursos Hídri$\cos (\mathrm{GRH})$ surge para desenvolver o gerenciamento da água de maneira integrada, a fim de maximizar o bem-estar econômico e social de maneira equitativa, sem comprometer a sustentabilidade dos ecossistemas vitais (Global Water Partnership, 2000).

É necessário estabelecer e melhorar os Sistemas de GRH, realizando uma gestão sustentável e eficiente da água e controlando rigorosamente os principais fatores que a influenciam. Na prática, a avaliação oferece subsídios para a GRH (Wang, 2016), permitindo que os usuários avaliem medidas relacionadas aos recursos hídricos, desempenho de diversas políticas de gestão (Yilmaz \& Harmancioglu, 2010a) em termos de critérios econômicos, sociais e ambientais (Yilmaz \& Harmancioglu, 2010b).

Dessa forma, a Avaliação de Desempenho (AD) é ferramenta útil para examinar a racionalidade do Sistema de GRH e realizar a utilização sustentável e eficiente dos recursos hídricos (Wang, 2016). Nesse contexto, conhecer o que já tem sido investigado parece ser o primeiro passo para a compreensão do estágio da área e ter subsídios para apontar oportunidades de pesquisa no intuito de contribuir para a GRH. Diante do exposto, a questão problema do estudo é: Quais são as características dos estudos que tratam da Gestão de Recursos Hídricos sob a ótica da Avaliação de Desempenho?

A partir do problema apresentado, o objetivo desta pesquisa é mapear, na literatura científica internacional, características dos estudos que avaliem o desempenho da Gestão de Recursos Hídricos, de modo a contribuir para sua preservação no âmbito social, econômico e ambiental. Para alcançar este objetivo, foi utilizado o instrumento de intervenção Knowledge Development Process-Constructivist (ProKnow-C).

Segundo o que foi levantado por Borowski e Hare (2007), como sugestões de pesquisas futuras, existe a necessidade de se aprimorar a compreensão dos pesquisadores sobre procedimentos e ferramentas para a GRH. Sendo assim, a presente pesquisa justifica-se pelo fato de não terem sido encontrados trabalhos que se dispusessem a analisar oportunidades de pesquisa para o fragmento da literatura científica, relativo à GRH substanciada pela AD; e confere viabilidade, pelo acesso aos artigos científicos das bases Scopus e Web of Science.

Sua justificativa se estende ao contexto ambiental e social, pelo incentivo do gerenciamento adequado e consequente preservação dos recursos hídricos que, direta ou indiretamente, afeta a sociedade como um todo, já que se trata de um recurso indispensável para a vida.

Quanto ao caráter prático da pesquisa, este justifica-se pela necessidade de se desenvolverem ferramentas apropriadas de apoio à decisão para ajudar tomadores de decisão a confrontarem a natureza mal estruturada do processo de avaliação dos recursos hídricos (Makropoulos, Natsis, Mittasand, \& Butler, 2008). O presente estudo visa dar este direcionamento necessário aos gestores para o desenvolvimento destas ferramentas que avaliem o desempenho deste recurso de maneira eficaz, segundo o exposto na literatura.

\section{REFERENCIAL TEÓRICO}

\subsection{GESTÃO DE RECURSOS HÍDRICOS (GRH)}

A água desempenha um papel significativo no desenvolvimento social e na sobrevivência da humanidade. Todavia, essa importância não era tão reconhecida no passado, visto que a água era considerada um recurso natural que não precisava ser protegido (Ren et al., 2013). Porém, com o crescimento populacional, a poluição (Yilmaz \& Harmancioglu, 2010a), o rápido crescimento econômico, as atividades destrutivas da humanidade (Ren et al., 2013), as mudanças climáticas e os grandes processos industriais, colocaram grande ênfase na disponibilidade de água (Manzardo et 
al, 2016). Desse modo, a GRH se tornou cada vez mais importante para a preservação desse recurso (Ren et al., 2013).

Melhorar a GRH é considerado um grande desafio que afeta usuários, formuladores de políticas e empresas (Manzardo et al., 2016). A escassez de água doce é reconhecida como uma das principais preocupações ambientais no centro dos debates internacionais, visto que um terço da população mundial vive em regiões escassas de água e o aumento dessa escassez é esperado no futuro (Manzardo et al., 2016), aumentando a competição entre os usuários da água (Hassanzadeh, Elshorbagy, Wheater \& Gober, 2016). Como os recursos de água doce estão diminuindo em quantidade e qualidade, a GRH é mais importante do que nunca e é amplamente aceito que a Gestão Integrada de Recursos Hídricos (GIRH) é o caminho a seguir (Yilmaz \& Harmancioglu, 2010b).

Enquanto a GRH busca maximizar o bem-estar econômico e social resultante de maneira equitativa sem comprometer a sustentabilidade dos ecossistemas vitais (Ren et al., 2013), a GIRH visa gerenciar os setores de água sujeitos a vários objetivos de maneira integrada, considerando as dimensões sociais, econômicas e ambientais (Yilmaz \& Harmancioglu, 2010b). Furlong, Brotchie, Considine, Finlayson e Guthrie (2017) definem a GIRH como o planejamento coordenado de todos os serviços de água (abastecimento de água, esgoto e drenagem), considerando oportunidades descentralizadas de água residual e reutilização de águas pluviais e a consideração explícita de habitabilidade e proteção do ecossistema. A GIRH avalia o desenvolvimento sustentável dos recursos hídricos, taxa de utilização desses recursos e os benefícios econômicos correspondentes. Por conta disso, a utilização racional dos recursos hídricos é propícia ao rápido desenvolvimento econômico (Wang, 2016).

A GRH tradicional, que considera os investimentos em melhoria da oferta de água em dimensões regionais por meio de análises econômicas, está sendo substituída pela gestão sustentável da água (Yilmaz \& Harmancioglu, 2010a). Novas estratégias estão na direção de considerar o desenvolvimento socioeconômico, o desenvolvimento regional e a avaliação econômica que enfatizam a redução da demanda de água e a melhoria da eficiência do uso desta (Ren et al., 2013). Um exemplo dessas estratégias é a pegada hídrica, água virtual ou água incorporada, sendo definida como o volume total de água doce direta e indiretamente necessária para produzir uma mercadoria ou um serviço (Shao \& Chen, 2013).

Na contemporaneidade, para avaliar a pegada hídrica de um produto, processo ou organização utiliza-se a Water Footprint Assessment (WFA), que é o resultado da contabilização do volume total de água doce utilizada direta ou indiretamente para produzir um produto e a ISO 14046, uma avaliação abrangente dos possíveis impactos ambientais relacionados à água de um produto (Manzardo et al., 2016). Segundo a ISO 14046, a pegada hídrica precisa ser considerada como um impacto e leva em conta a disponibilidade de água e as mudanças na qualidade desta ao longo de toda a cadeia de suprimentos (Wessman et al., 2014). Deste modo, com mais da metade da humanidade urbanizada, há necessidade urgente de se ter uma visão integrada e holística do suprimento e demanda de água nas cidades (Fattahi \& Fayyaz, 2010), tornando a GRH um fator crítico na sustentabilidade urbana (Marlow, Moglia, Cook, \& Beale, 2013).

As áreas urbanas são as principais responsáveis pelas mudanças ambientais globais, pois constituem $75 \%$ da demanda global de recursos, devido à sua grande influência e impacto. Estas áreas podem atuar tanto como a causa, quanto a solução para os desafios ambientais globais e são essenciais para alcançar o desenvolvimento sustentável (Feingold, Koop, \& Leeuwen, 2018). Nesse sentido, a gestão integrada da água urbana é uma questão importante e crítica em todas as cidades e países. Sua abordagem é dada ao impacto coletivo de todos os possíveis processos urbanos relacionados à água, tais como saúde humana, proteção ambiental, qualidade das águas receptoras, demanda urbana, satisfação dos consumidores, os benefícios nacionais e os riscos sociais (Fattahi \& Fayyaz, 2010). 
Assim, os governos passam a demandar a prestação de serviços de água urbanos melhorados e ampliados tanto nos países em desenvolvimento, quanto nos desenvolvidos (Poustie et al., 2015). Porém, existem diversos níveis de responsabilidade para o gerenciamento de águas urbanas (serviços públicos integrados horizontalmente, governo estatal/local, empresas de água ou municípios integrados verticalmente, etc.), em diversos países (Furlong et al., 2017).

A GRH requer ações em vários níveis, incluindo governança (políticas e legislação), gestão, inovação tecnológica e mudança de comportamento (Gössling, 2015). É necessário enviar mais esforços para rastrear a sustentabilidade da água urbana no nível organizacional e na cidade, a fim de avaliar o progresso das políticas municipais. Para que os serviços de água urbana sejam sustentáveis a longo prazo é necessário um governo responsável no âmbito nacional e local (Carden \& Armitage, 2013).

O emergente paradigma da legislação ambiental da União Europeia (por exemplo, UE Water Framework Directive), internaliza princípios de Gestão Integrada da Água, prevenção da poluição e um conceito mais completo de sustentabilidade que apresenta não só aspectos ecológicos ou econômicos, mas também sociais e institucionais, como a participação dos stakeholders (Makropoulos et al., 2008).

Além da UE Water Framework Directive, Rennings e Rammer (2011) abordam outras políticas de GRH, como a German Drinking Water Directive. Todavia, os autores indicam que as políticas ambientais de gestão da água não desencadeiam sucessos na inovação das empresas. Isso pode ser explicado pelo fato de muitas regulamentações datarem dos anos 1980 e início dos anos 1990, ou seja, as empresas que ainda inovam nesses padrões acabam introduzindo novos produtos em seu portfólio que já foram introduzidos por outras empresas muitos anos antes, adotando tecnologias já existentes (Rennings \& Rammer, 2011).

Outros obstáculos podem ser encontrados na GRH, tais como as condições socioeconômicas (pobreza generalizada dificulta os esforços para aumentar a consciência ambiental e para introduzir instalações de tratamento de esgoto e sistemas de irrigação mais eficientes, financiamentos para o Plano Diretor e falta de envolvimento dos stakeholders) e políticas do país (instituições políticas fracas e instáveis no país). Também é importante observar que é preciso aplicar medidas de gestão que reflitam a sua realidade, sendo um equívoco aplicar um gerenciamento oriundo de países desenvolvidos em um país subdesenvolvido (Rieckermann, Daebel, Ronteltap, \& Bernauer, 2006).

Os critérios conflitantes também podem ser uma dificuldade no processo de tomada de decisões, uma vez que é necessário lidar com implicações técnicas, ambientais e sociais dos recursos hídricos, junto com critérios econômicos, a fim de alcançar decisões confiáveis e resultados adequados voltados a tomada de decisões (Hashemi et al., 2013).

\subsection{AVALIAÇÃO DE DESEMPENHO}

As práticas e o conhecimento da Avaliação de Desempenho nas mais diversas áreas foram se consolidando ao longo dos anos. Essa evolução teria surgido com as técnicas básicas de gerenciamento de grandes negócios dos primos Du Pont, em 1910 (Neely, 1999). Porém, desde o seu surgimento, como resultado das mudanças no mercado mundial, a área direcionou seus estudos para investigação das demandas que foram surgindo (Ghalayini \& Noble, 1996).

Inicialmente, esta avaliação foi desenvolvida apenas por meio de medidas de desempenho tradicionais, oriundas da contabilidade (Ghalayini \& Noble, 1996; Neeley, 1999). Essa prática levou a críticas, pois as medidas eram centradas na contabilidade, as métricas refletiam o desempenho passado, não representavam a estratégia da organização, a informação gerada era de difícil interpretação do que deveria ser modificado nas áreas/departamentos da organização, tinham um formato de divulgação pré-determinado, dentre outros aspectos (Ghalayini \& Noble, 1996), uma vez 
que não informava e não analisava o que realmente era importante para a organização (Neely, 1999).

A partir disso, a Avaliação de Desempenho passou a observar as demandas mundiais que promoveram mudanças na gestão das organizações e direcionou esforços para atender a essas demandas, como a consideração de medidas de Avaliação de Desempenho financeiras e não financeiras, a concepção de medidas com base nas estratégias da organização, a utilização de métricas compreensíveis, foco na melhoria contínua, consideração de aspectos externos da organização, entendendo que deve atender às necessidades e os interesses dos seus stakeholders, a comunicação interna, externa e a legitimidade institucional e o acompanhamento do dinamismo do mercado para ajuste do processo de avaliação utilizado na organização (Carneiro-da-Cunha et al., 2016; Ghalayini \& Noble, 1996; Melnyk et al., 2014; Neely, 1999). Assim, os Sistemas de Avaliação de Desempenho (SADs) foram sendo propostos e os estudos sobre esta temática foram ocorrendo com base nessas demandas, especialmente, nas últimas três décadas. A seguir, resgatam-se aportes teóricos que resumem esses estudos e suportam o estágio atual da área.

A Avaliação de Desempenho proposta por Neely et al. (1995), alerta sobre a importância do SAD refletir os objetivos, a missão e as estratégias da empresa, uma vez que o resultado da avaliação influencia o comportamento dos funcionários, quer seja pela motivação, monitoramento e estímulo de aprendizagem. Bititici et al. (2012) argumentam a existência dessa influência da AD ao afirmarem que é um fenômeno social no qual os comportamentos são moldados pelos valores e percepções dos indivíduos e da comunidade em que opera, assegurando a realização dos objetivos da organização, planos e metas, afetando as ações de todo o grupo envolvido. Assim, a atividade de apresentação do resultado da avaliação (feedback) para os funcionários proporciona à capacidade destes aprenderem sobre o que está e o que não está funcionando, bem como, os gestores identificarem se é necessário e onde o SAD deve ser reavaliado/ajustado (Neely et al., 1995).

Desse modo, percebe-se que a aprendizagem se faz presente, especialmente, nos modelos de maturidade no campo da Avaliação de Desempenho, pois, seguindo o modelo de maturidade, os gestores começam a se reunir em discussões abertas para tratar de outros assuntos que antes não faziam, começando a refletir sobre suas práticas de gestão de desempenho. Assim, pode-se realizar uma autocrítica, introduzindo novas ideias, propondo mudanças e conhecendo práticas de outras empresas (Bititci, Garengo, Ates, \& Nudurupati, 2014).

Essas autocríticas das práticas de gestão de desempenho estão presentes na abordagem de Bourne, Mills, Wilcox, Neely e Platts (2000), como uma importante fase do ciclo de vida de um SAD, o da retroalimentação do Sistema. Segundo Bourne et al. (2000), a primeira fase do ciclo de vida é a concepção do $S A D$, com a identificação dos objetivos e definição das métricas para mensurá-los, seguido pela fase de implementação, para que os dados possam ser coletados, verificados, analisados e distribuídos. Segundo Neely et al. (1995), ainda na fase da implementação, o Sistema também deve interagir com o ambiente interno e externo. A terceira etapa seria o uso do SAD, em que os gestores avaliam o atendimento aos objetivos estratégicos da organização, gerando um feedback do desempenho da empresa. O último passo proposto pelos autores é a revisão da eficácia de todo o Sistema, para que este se mantenha atualizado e continue alinhado com os propósitos da organização, podendo alterar a estratégia da empresa. É interessante ressaltar que, segundo o estudo de Choong (2014), o termo 'Sistema' na Avaliação de Desempenho deve ser utilizado caso seja analisado como um todo, como é o caso do estudo de Bourne et al. (2000), pois, se não estiver baseado na abordagem da Teoria dos Sistemas, este não pode tirar proveito da sinergia, inexistindo um sistema, em sua plenitude.

Já na fase do uso, para que seja possível gerar um feedback de um SAD, a comunicação é imprescindível, pois, apenas pela comunicação com os stakeholders, é que o desempenho pode realmente ser avaliado. Ou seja, é pela comunicação que são identificados os objetivos e prioridades de 
uma organização, auxiliando a tomada de decisões (Choong, 2014). A comunicação interna e externa, também é considerada um dos papéis efetuados pela Avaliação de Desempenho, ou seja, funções ou motivos pelo quais são executados os SAD (Franco-Santos et al., 2007).

Por outro lado, Camp e Braet (2016) investigaram os fatores que podem levar ao fracasso dos SAD, propondo uma taxonomia das falhas dos SAD. Essas falhas podem ocorrer no nível métrico, com questões relacionadas à coleta de dados (o quê, como, quanto e quando medir). Essas dúvidas podem ocorrer pela falta de conhecimento, por razões de praticidade, pela aplicação de métricas desequilibradas, não objetivas, entre outros fatores (Camp \& Braet, 2016). Cumpre observar que o compromisso da administração é essencial para uma implementação bem-sucedida de um SAD (Bourne et al., 2000), e a falta de apoio da gerência pode levar ao fracasso do Sistema (Camp \& Braet, 2016).

Um dos conceitos mais abordados, quando discutido o tema Avaliação de Desempenho, é o elaborado por Neely et al. (1995, p. 80), em que "uma medida de desempenho pode ser definida como uma métrica usada para quantificar a eficiência e/ou a eficácia de uma ação". Embora amplamente utilizados, os termos-chave medida e métrica, na AD geralmente não são bem definidos (Melnyk et al., 2014). Na tentativa de esclarecer essas distinções, Melnyk et al. (2014) sinalizam uma métrica com algo a mais que uma medida de desempenho. Portanto, uma medida de desempenho é informativa, quantificando o que está acontecendo: elemento fundamental para que um SAD funcione (Franco-Santos et al., 2007).

Uma métrica constitui-se de sua medida, mas adiciona um padrão de desempenho ou de meta aceitável para ser atingido, considerando o bom e o mau desempenho para orientar a direção da organização, ou seja, demonstrando consequências relativas a estar acima ou abaixo da meta estipulada (Melnyk et al., 2014). Desse modo, as métricas são blocos de construção fundamentais para um SAD (Melnyk et al., 2014). Assim, o conceito do Neely et al. (1995) é reestruturado como uma medida de desempenho, sendo o instrumento usado para quantificar a eficiência e/ou a eficácia da ação (Melnyk et al., 2014).

\section{METODOLOGIA DA PESQUISA}

O enquadramento metodológico deste estudo, quanto à natureza do seu objetivo, refere-se a uma pesquisa exploratório-descritiva, pois visou construir conhecimento nos pesquisadores acerca da temática de avaliação de desempenho na gestão dos recursos hídricos, ao mesmo tempo em que descreve características das variáveis selecionadas para investigação do tema (Richardson, 2014). Foram utilizados dados primários na seleção do Portfólio Bibliográfico (PB), já que as delimitações foram realizadas pelos pesquisadores em todas as escolhas demandadas durante o processo, além de realizar análise crítica sobre os artigos do PB; e dados secundários pelas próprias publicações que compõem o PB. A abordagem do problema caracteriza-se como qualitativa, visto que os dados investigados foram interpretados com auxílio do instrumento de intervenção construtivista.

O instrumento de intervenção foi o Knowledge Development Process-Constructivist (ProKnowC), cujo objetivo é construir conhecimento, inicialmente, para o pesquisador 'debruçado' na investigação e para os interessados pela disseminação de interpretações e significados, por este aferido, diante das variáveis investigadas (Dutra, Ripoll-Feliu, Fillol, Ensslin, \& Ensslin, 2015; Thiel, Ensslin, \& Ensslin, 2017). O ProKnow-C é composto por quatro etapas: (i) seleção de um PB sobre o tema; (ii) análise bibliométrica; (iii) análise sistêmica; e, iv) identificação de oportunidades de pesquisas (Dutra et al., 2015). Esse estudo valeu-se das etapas (i), (ii) e (iv), por melhor se enquadrarem com as lacunas que a pesquisa pretende preencher.

A seleção dos artigos que compõem o PB foi realizada em março de 2018, considerando somente os artigos publicados em inglês, a partir do ano de 2000, em periódicos (journals) integran- 
tes das bases de dados Scopus e Web of Science. A escolha por estudos de língua inglesa se dá pelo intuito de espelhar o desenvolvimento do tema na literatura internacional, sem haver um direcionamento para estudos nacionais, propondo aumentar a viabilidade do presente estudo em outros países. A Figura 1 ilustra os procedimentos adotados para a seleção do PB.

Com o PB selecionado, iniciou-se o tratamento dos dados para conhecer a literatura sobre o tema pesquisado. Para tal, uma análise bibliométrica das variáveis básicas possibilitou identificar autores, instituições e redes de colaboração entre autores, quantidade de publicações por ano e apresentação de um modelo de ferramentas utilizadas nos artigos.

Figura 1 - Seleção do Portfólio Bibliográfico

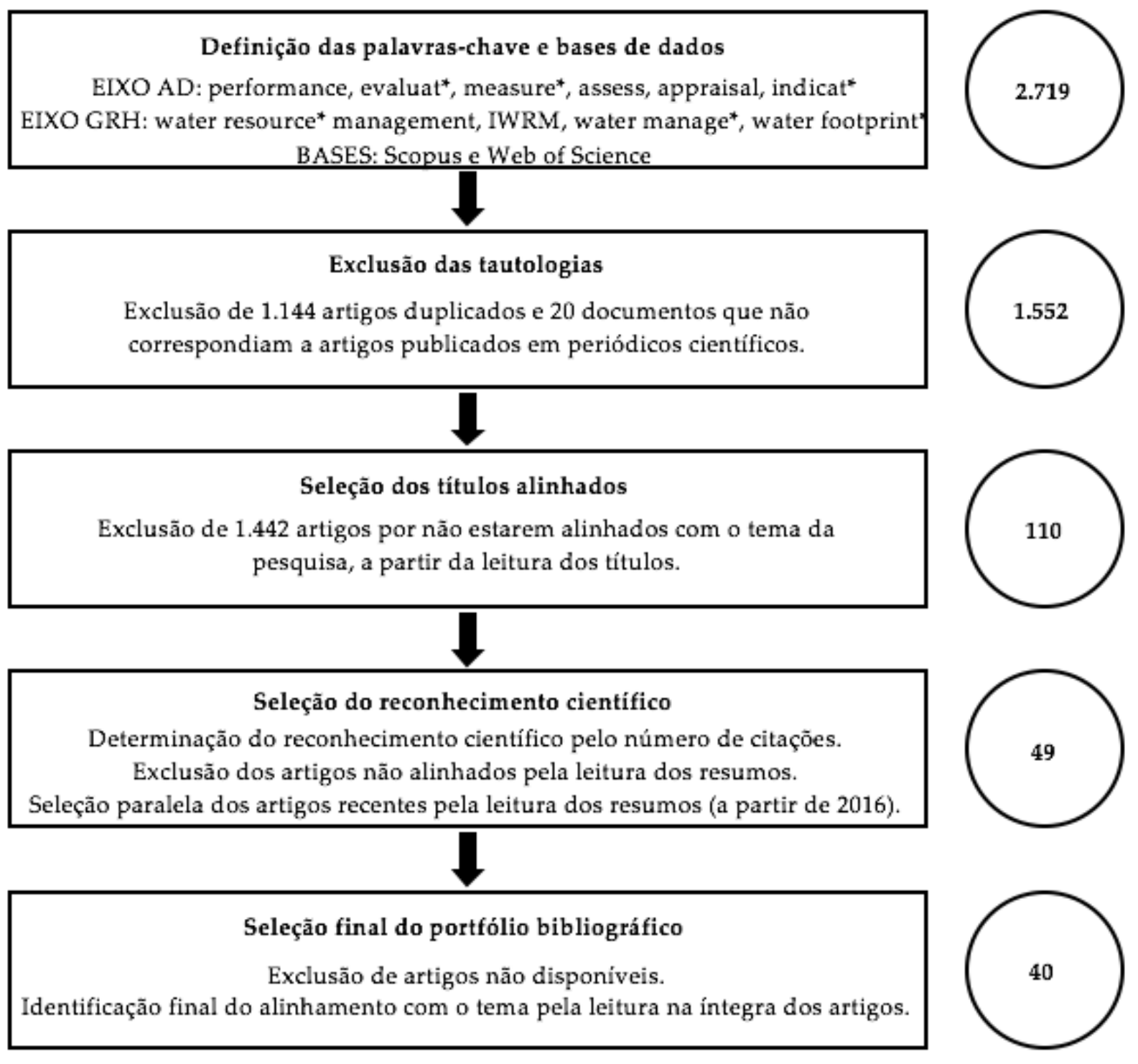

Fonte: Elaborado pelos autores.

Na sequência, a bibliometria é direcionada para a análise avançada a fim de proporcionar uma visão mais aprimorada da presença da $\mathrm{AD}$ na GRH, em que se alia a literatura reconhecida de $\mathrm{AD}$ ao PB. Assim, realizou-se a análise dos conceitos propostos por Melnyk, Bititci, Platts, Tobias e Andersen (2014) sobre medidas e métricas, conforme detalhado no referencial teórico, em comparação às definições encontradas na literatura investigada. Para esses, uma medida é capaz apenas de quantificar e verificar o desempenho, enquanto uma métrica possui um nível de detalhamento 
crítico superior a esta, apresentando também uma meta de desempenho, indicando o que seria um bom ou mal desempenho, e a consequência de se estar acima ou a baixo desta meta (Melnyk et al., 2014).

Os níveis, propostos por Neely, Gregory e Platts (1995), segundo os quais os Sistema de Avaliação de Desempenho (SAD) podem ser desenvolvidos (medidas individuais de desempenho, conjunto de medidas de desempenho e relação entre o sistema de avaliação de desempenho e o ambiente), também foram investigados, bem como, as finalidades para as quais a AD foi realizada e a fonte de demanda das informações da AD.

Na sequência, desenvolveu-se uma categorização das preocupações que apresentaram mais ocorrências no PB. Essas podem ser em nível de medidas, métricas ou apenas de seus objetivos e indicadores, permitindo visão mais ampla dos atributos utilizados na literatura científica que auxiliam na elaboração e execução de uma Avaliação de Desempenho apropriada na GRH. Sabendo que a GRH pode ser considerada um processo interativo de tomada de decisão que ajuda os gestores a reconhecer como suas atividades podem ter impactos na sustentabilidade de longo prazo (Hashemi, Bazargan, \& Mousavi, 2013), a categorização foi realizada por meio do triple bottom line, definição desenvolvida por Elkington (1998) para contextualizar a sustentabilidade como busca de três pilares do desenvolvimento econômico, qualidade do meio ambiente e justiça social. Segundo Hubbard (2009), o triple bottom line é candidato apropriado para a avaliação de desempenho organizacional sustentável.

Por meio de uma análise avançada, também foram investigadas as falhas no nível métrico dos indicadores/ferramentas nos estudos do PB com base na taxonomia de Camp e Braet (2016), visto que os autores identificaram fatores que podem levar ao fracasso dos SAD, principalmente relacionadas à coleta de dados (o quê, como, quanto e quando medir).

Com o conhecimento gerado, buscou-se com o desenvolvimento desta pesquisa, sinalizar as contribuições para a área, identificando oportunidades de pesquisas para os pesquisadores e desafios para os gestores das organizações com base no aporte teórico das variáveis avançadas.

\section{RESULTADOS}

\subsection{ANÁLISE BIBLIOMÉTRICA - VARIÁVEIS BÁSICAS}

Identificou-se que Gordon Huang é o autor com o maior número de artigos no PB. Huang atua e contribui no campo de Sistemas Gerenciais Ambientais, proporcionando uma gama de informações úteis para o desenvolvimento de SAD. Outros autores apresentaram mais de um trabalho desenvolvido no $\mathrm{PB}$, porém, não foram considerados autores destaques por não serem da área ou por apresentarem estudos voltados apenas à GRH, como é o caso de Baris Yilmaz e Nilgun B. Harmancioglu.

Com base nos dados dos autores presentes no PB, a Figura 2 busca identificar a existência de rede de colaboração entre coautores, de onde se identificam grupos de autores que trabalharam juntos e publicam um ou dois artigos, mas inexiste a formação de redes. 
Figura 2 - Rede de colaboração entre coautores

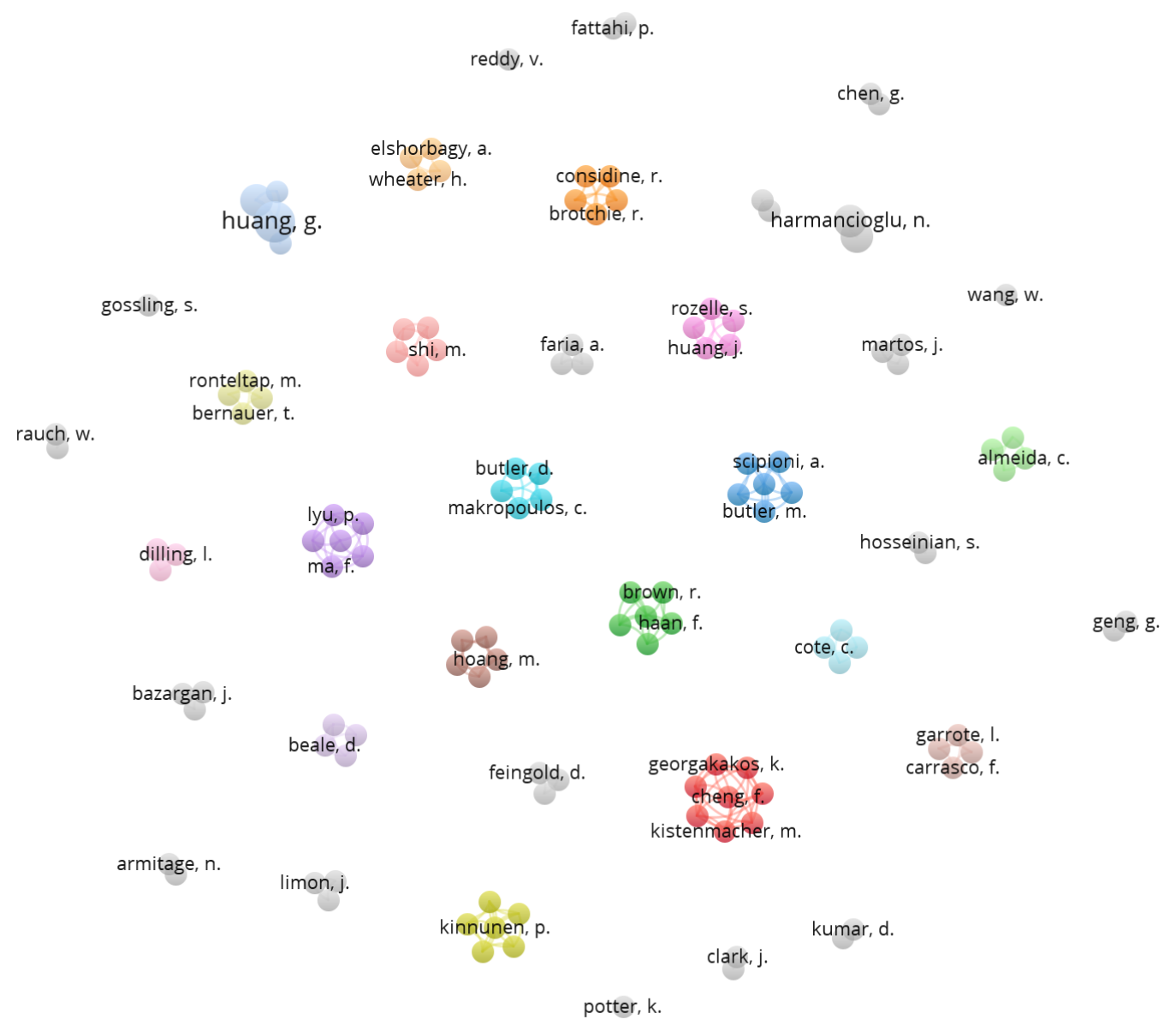

Fonte: Elaborado pelos autores (VOSviewer).

Essa inexistência de redes pode ter ocorrido devido à emergência do tema Avaliação de Desempenho da GRH, conforme exposto no Gráfico 1. A primeira publicação ocorreu em 2000, pelo autor considerado destaque na área, Gordon Huang, em parceria com Daniel Loucks (Huang \& Loucks, 2000). Com essa publicação, até o ano de 2009, encontra-se uma linha constante de publicações, embora em pouca quantidade: entre um ou dois artigos. A grande maioria das publicações ocorreu a partir de 2010, intensificando a ideia de que a Avaliação de Desempenho da GRH é um tema emergente, com potencial para futuras pesquisas. 
Gráfico 1 - Publicações por ano

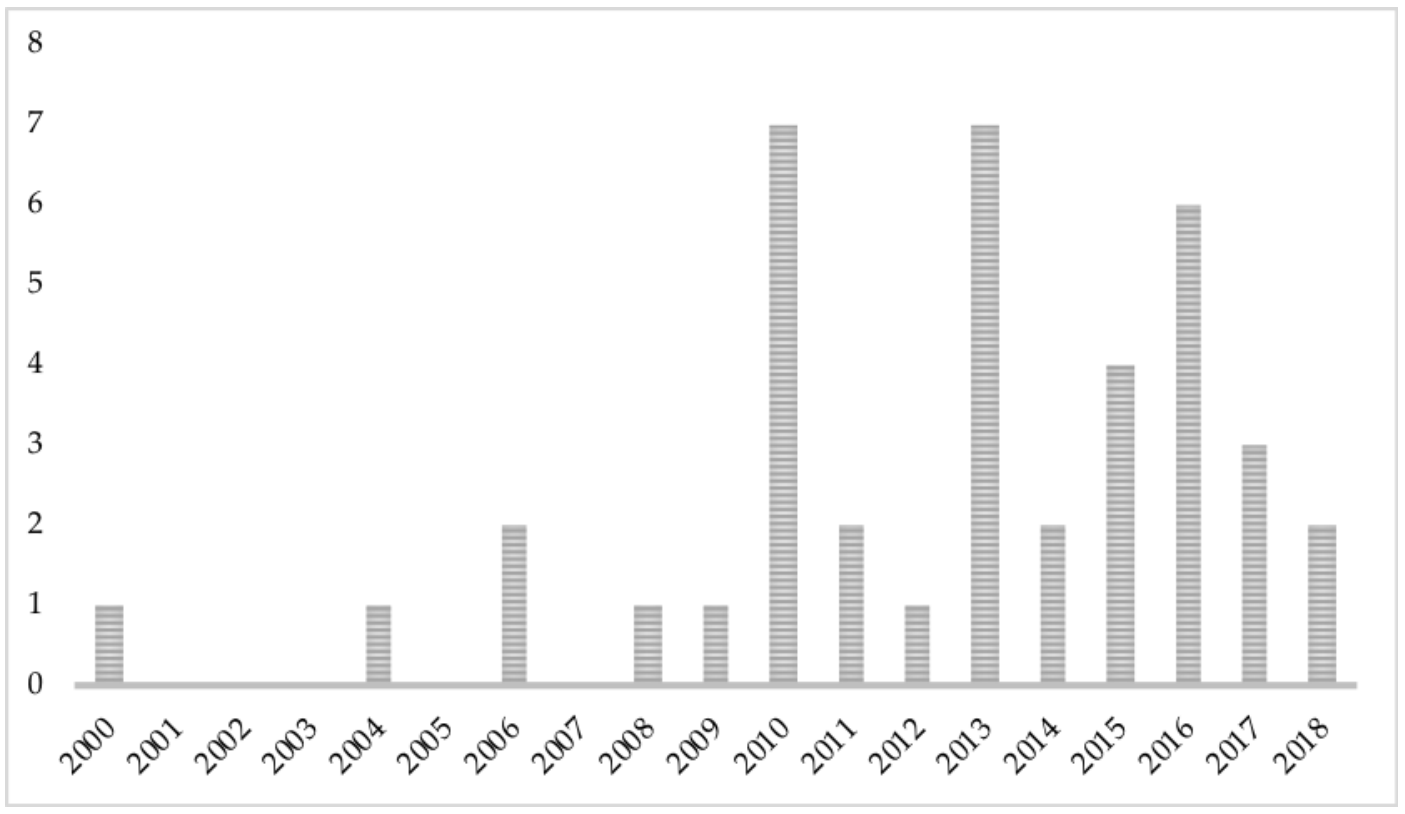

Fonte: Elaborado pelos autores.

A investigação da rede de colaboração entre as instituições dos autores do PB é apresentada na Figura 3. Conforme a Figura 3, a University of Regina, no Canadá, se destaca em quantidade de artigos. Esse fato pode ser compreendido pela University of Regina ser líder global em meio ambiente e sustentabilidade, especialmente na área de recursos aquáticos, investindo fortemente no tema, com \$ 13 milhões do Instituto de Mudança Ambiental e Sociedade (IECS) e sete subsídios bemsucedidos da Fundação de Inovação do Canadá (CFI), e quatro do Canada Research Chairs (University of Regina, 2018). Além disso, é importante ressaltar que Gordon Huang, autor destaque do tema, é professor de Engenharia de Sistemas Ambientais na Instituição e um dos Canada Research Chairs. 
Figura 3 - Rede de colaboração entre instituições
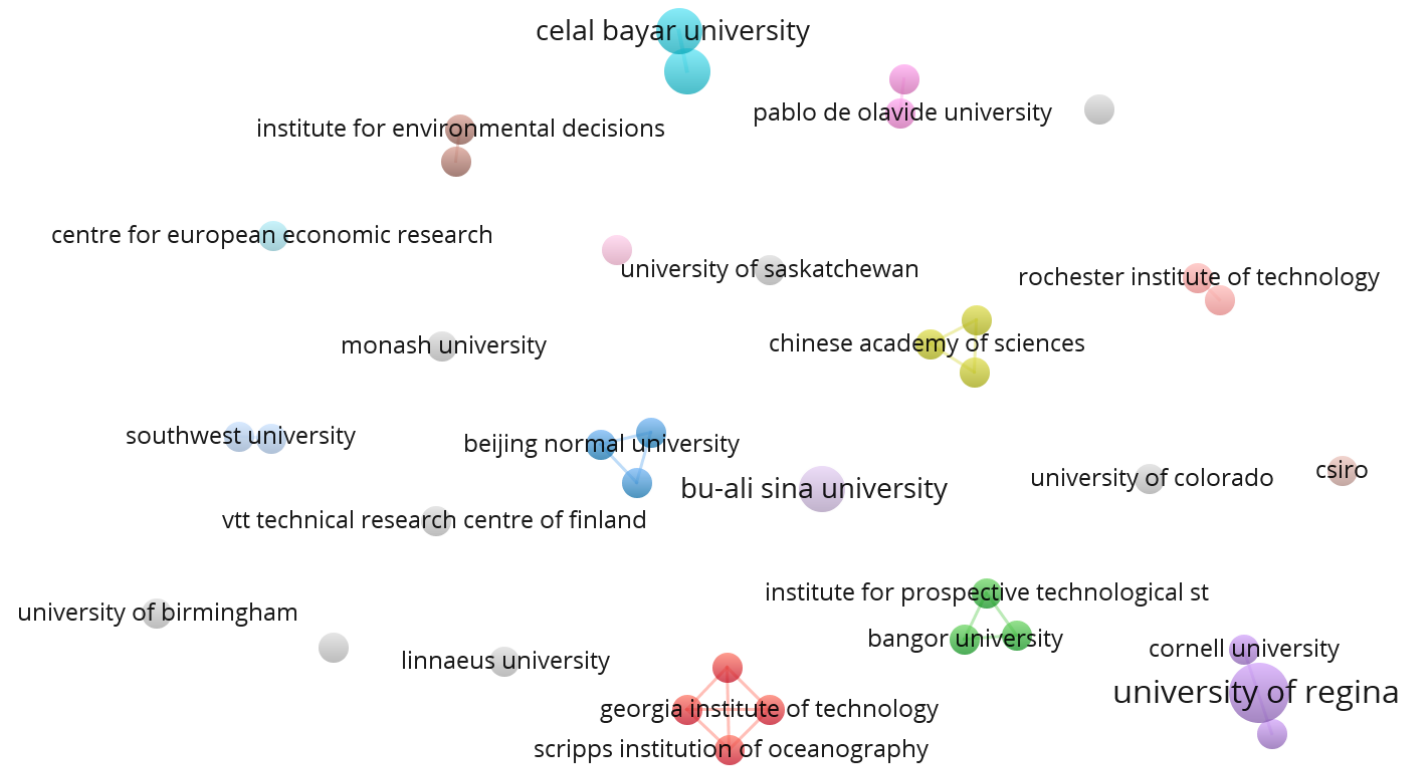

Fonte: Elaborado pelos autores (VOSviewer)

Com o intuito de auxiliar na GRH e em possíveis pesquisas futuras sobre o tema, identificaram-se as ferramentas utilizadas para a realização desta gestão, de acordo com o Quadro 1.

Quadro 1 - Ferramentas utilizadas

\begin{tabular}{|c|c|}
\hline Ferramenta & Artigo \\
\hline ISO 14046 & Manzardo et al. (2016) \\
\hline Smart Water Management Platform (SWAMP) & Hassanzadeh et al. (2016) \\
\hline Storm Water Management Model (SWMM) & Urich \& Rauch (2014) \\
\hline Urban Water Optioneering Tool (UWOT) & Makropoulos et al. (2008) \\
\hline Water Evaluation and Planning system (WEAP) & Yilmaz \& Harmancioglu (2010a, 2010b) \\
\hline Water Footprint Assessment & $\begin{array}{c}\text { Gössling (2015); Manzardo } \text { et al. (2016); Shao \& Chen } \\
\text { (2013); Wessman } \text { et al. (2014) }\end{array}$ \\
\hline
\end{tabular}

Fonte: Elaborado pelos autores.

O uso de tais ferramentas espelha o contexto de cada um dos ambientes estudados nas pesquisas. Todavia, uma ferramenta se destaca, com aplicabilidade em diversos cenários, o Water Footprint Assessment. Esta ferramenta é capaz de avaliar o volume de água doce utilizado para produzir uma unidade de bem ou serviço, medido ao longo de toda a cadeia de suprimento (Gössling, 2015; Manzardo et al., 2016). 
De acordo com Wessman et al. (2014), a ferramenta se desenvolveu rapidamente, gerando várias iniciativas de diferentes instituições e organizações. Essa ampla aceitação e emprego da mesma demonstra a importância e usabilidade de ferramentas abrangentes, que facilmente se adequem as mais diversas esferas, com condições acessíveis e estratégicas. O desenvolvimento de mais ferramentas com essas características auxiliaria na gestão e AD dos recursos hídricos em extensão muito mais ampla.

\subsection{ANÁLISE BIBLIOMÉTRICA - VARIÁVEIS AVANÇADAS}

Diante da importância do uso de indicadores de desempenho e das implicações 'problemáticas' da AD quando do uso inadequado de medidas e métricas (Choong, 2014), uma análise desses conceitos no Portfólio Bibliográfico se faz necessária. Esta análise demonstra como esses conceitos foram usados pelos autores (Gráfico 2), comparando-os com a interpretação destes conforme a visão abordada por Melnyk et al. (2014), proporcionando a evidenciação de alinhamento, ou não, de conceitos sobre os termos empregados na literatura.

Gráfico 2 - Evidenciação de medidas, métricas e indicadores nos artigos

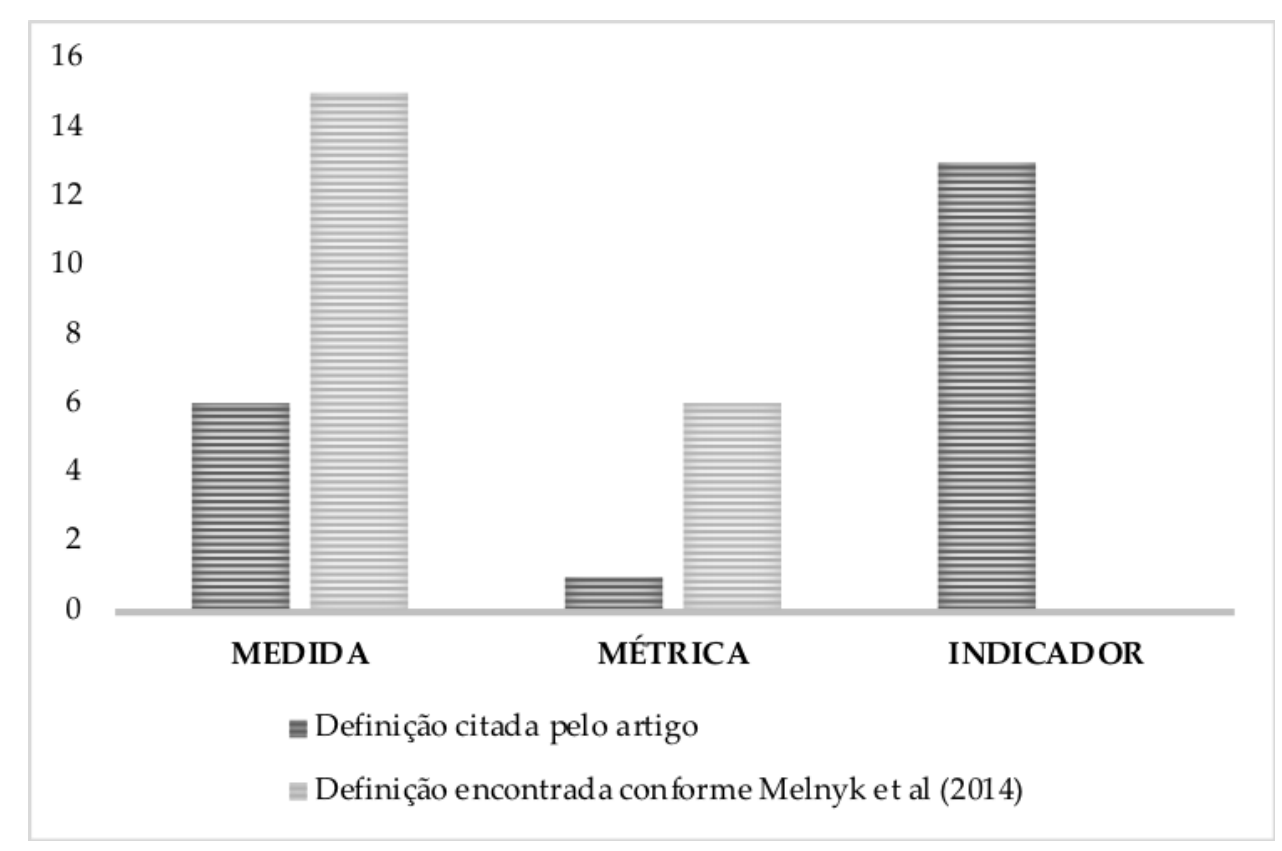

Fonte: Elaborado pelos autores.

Dentre os 16 artigos do PB que expuseram suas preocupações e/ou objetivos a serem avaliados para auxiliar na GRH, 93,75\% fizeram uso de medidas individuais de desempenho para promover a devida avaliação, nível mínimo para tornar um SAD possível (Melnyk et al., 2014). Todavia, apenas 37,50\% dos artigos fizeram uso da denominação medidas para tratar destas.

Referindo-se às métricas, a exposição do termo é ainda menor. Apenas um artigo utilizou essa denominação, entretanto seis artigos (37,50\%) as apresentam, mesmo não fazendo uso do termo métricas. Percebe-se que muitos dos artigos que evidenciam medidas e métricas as utilizaram apenas como uma extensão dos indicadores de desempenho, sem empregar nenhuma denominação específica. 
Cabe destacar que o termo indicador foi utilizado na grande maioria dos artigos, demonstrando o quanto o uso do termo é generalizado na temática da GRH. Os termos índices e atributos também foram apresentados em alguns artigos, evidenciados como "Outros" no Quadro 2.

Estes resultados vão de acordo com o exposto por Neely et al. (1995) e Franco-Santos et al. (2007), visto que, para os autores, embora sejam amplamente utilizados, os termos-chave da AD geralmente não são bem definidos e, consequentemente, acabam sendo empregados da maneira incorreta.

\section{Quadro 2 - Uso da terminologia medidas, métricas e indicadores no PB}

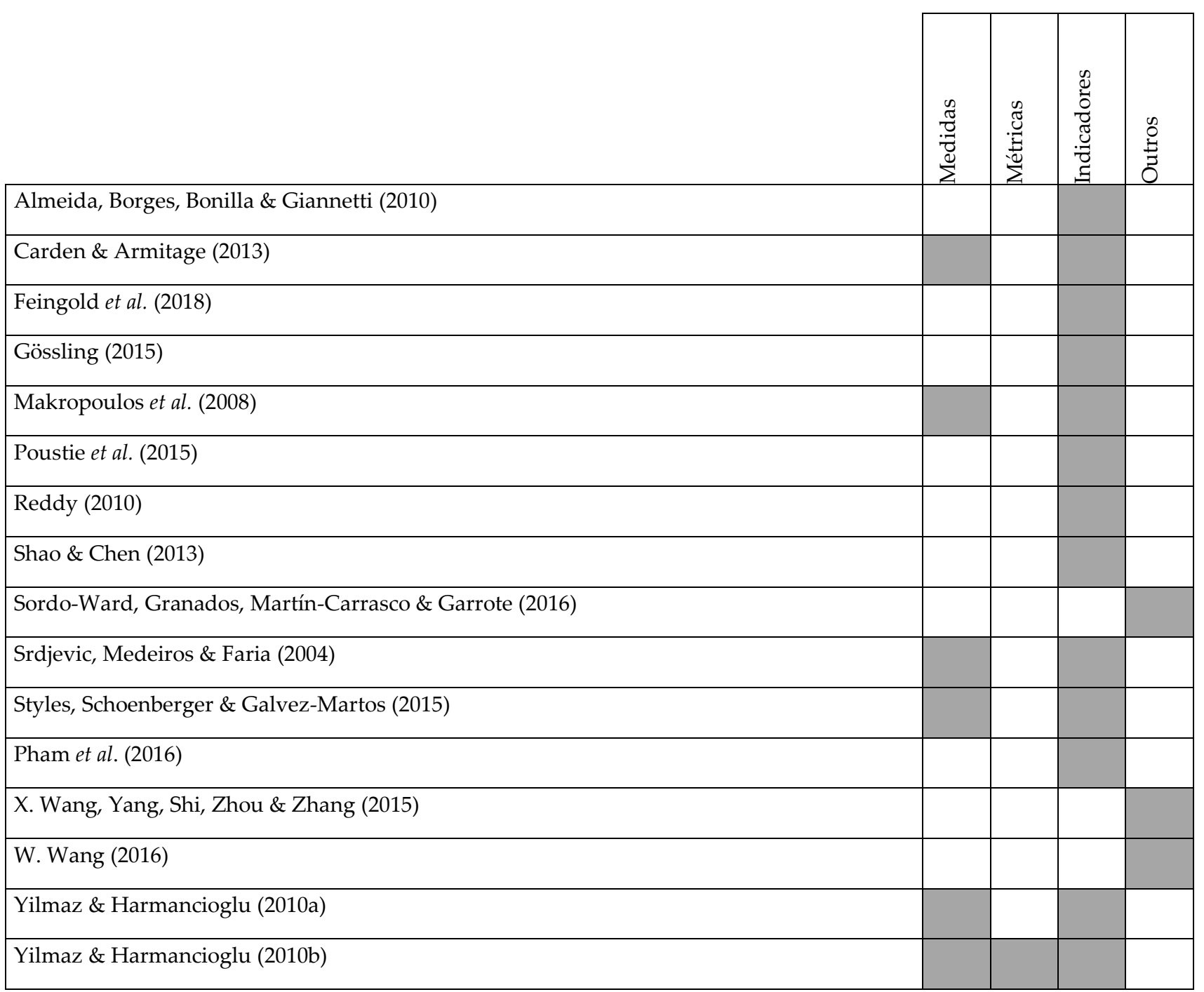

Fonte: Elaborado pelos autores.

Se tratando da configuração de um SAD, Neely et al. (1995) destacam que a AD pode ser tratada ou desenvolvida em três níveis, do mais simples ao mais completo: medidas individuais de desempenho, conjunto de medidas de desempenho como uma entidade e a relação/influência do ambiente nessas medidas. Embora o PB seja composto por 40 artigos, somente 15 apresentaram medidas individuais de desempenho e apenas nove evidenciaram um conjunto de medidas de desempenho e o relacionaram com o ambiente. Assim, apenas 22,50\% dos artigos do PB alinhamse ao aporte teórico de Neely et al. (1995).

A importância do uso de medidas de desempenho se dá pois, além de ser um processo de quantificação, seu efeito estimula a ação, gerando maior consistência para que as estratégias sejam 
realizadas (Neely et al., 1995). Sendo assim, a Figura 4 evidencia, dos 22,50\% artigos alinhados, quais foram as finalidades da realização da $\mathrm{AD}$, observando como os artigos aproximam a $\mathrm{AD}$ a realização de ações estratégicas para o gerenciamento dos recursos hídricos.

Mensurar o desempenho, ação básica para um SAD, é a finalidade de maior preocupação dos artigos. Gerar um diagnóstico, comparar desempenhos e, ainda mais importante para atingir estratégias, oferecer informações para a gestão, são objetivos e oportunidades geradas pela AD que não são fortemente reconhecidas pelos presentes trabalhos.

Dos nove artigos que evidenciaram um conjunto de medidas de desempenho e o relacionaram com o ambiente, apenas sete apresentaram uma estrutura de SAD alinhada à concepção atual da AD para os Sistemas, uma vez que foram elaborados com base nas características, metas ou problemas das bacias hidrográficas, nas entrevistas realizadas com os responsáveis ou pelos objetivos apontados pelos stakeholders como necessários. A relação desses Sistemas com os stakeholders demonstra a preocupação que existe com o ambiente externo quando se trata de um recurso natural indispensável para a vida. Alguns artigos ainda destacaram práticas de benchmarking como interação com o ambiente externo.

Um SAD verdadeiramente equilibrado forneceria aos gerentes informações relacionadas ao ambiente tanto interno quanto externo (Neely et al., 1995). Todavia, conforme apresentado na Figura 4, apenas $20 \%$ dos artigos que se alinham à proposta de Neely et al. (1995) fazem uso de informações de ambas as fontes.

Reconhecer estas fragilidades é essencial para instigar pesquisas na área que façam melhor aproveitamento das capacidades que um SAD pode proporcionar, gerando sistemas mais complexos baseados nos diversos ambientes, principalmente relacionados ao uso deste recurso escasso e indispensável que é a água.

Figura 4 - Finalidade para qual a AD é realizada e as fontes de demandas das informações geradas

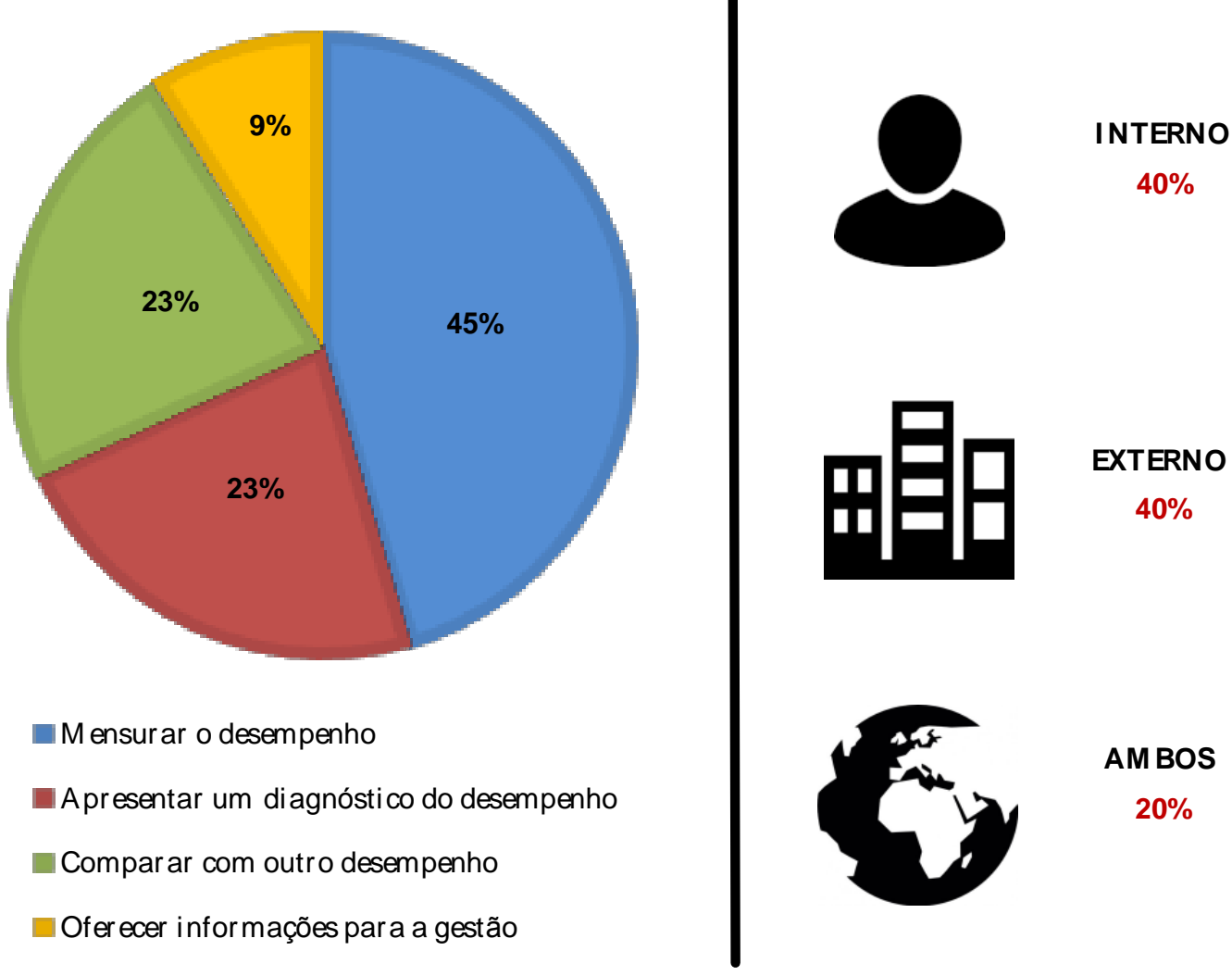

Fonte: Elaborado pelos autores. 
No nível individual de Avaliação de Desempenho, sabendo que este deve apresentar um padrão consistente de decisões e ações dentro da empresa (Neely et al., 1995), realizou-se uma categorização das preocupações com maiores ocorrências no PB (Quadro 3).

Quadro 3 - Indicadores na GRH

\begin{tabular}{|c|c|c|}
\hline Categoria & Preocupação/Objetivo & Artigos \\
\hline \multirow{10}{*}{ Ambiental } & Clima & Carden \& Armitage (2013); Feingold et al. (2018) \\
\hline & Consumo Água & $\begin{array}{l}\text { Carden \& Armitage (2013); Gössling (2015); Makropoulos et al. (2008); } \\
\text { Pham et al. (2016); Shao \& Chen (2013); Sordo-Ward et al. (2016); } \\
\text { Srdjevic et al. (2004); Styles et al. (2015); W. Wang (2016); Yilmaz \& } \\
\text { Harmancioglu (2010a, 2010b) }\end{array}$ \\
\hline & Eficiência no Uso Água & $\begin{array}{l}\text { Carden \& Armitage (2013); Styles et al. (2015); Yilmaz \& Harmancio- } \\
\text { glu (2010a, 2010b) }\end{array}$ \\
\hline & Escassez Água & Feingold et al. (2018); Reddy (2010); Srdjevic et al. (2004) \\
\hline & Impactos Ambientais & Makropoulos et al. (2008); Poustie et al. (2015) \\
\hline & Perda Água & Makropoulos et al. (2008); Pham et al. (2016) \\
\hline & Produção de Resíduos & Carden \& Armitage (2013); Feingold et al. (2018); Poustie et al. (2015) \\
\hline & Qualidade Água & Carden \& Armitage (2013); Feingold et al. (2018); Poustie et al. (2015) \\
\hline & $\begin{array}{l}\text { Uso de Produtos Quími- } \\
\text { cos }\end{array}$ & Makropoulos et al. (2008); Poustie et al. (2015) \\
\hline & Uso Energia & $\begin{array}{l}\text { Carden \& Armitage (2013); Gössling (2015); Makropoulos et al. (2008); } \\
\text { Poustie et al. (2015); Shao \& Chen (2013) }\end{array}$ \\
\hline \multirow{7}{*}{ Social } & Acessibilidade Água & Carden \& Armitage (2013); Makropoulos et al. (2008); W. Wang (2016) \\
\hline & Educação & Carden \& Armitage (2013); Feingold et al. (2018) \\
\hline & Empregos & Carden \& Armitage (2013); Feingold et al. (2018); X. Wang et al. (2015) \\
\hline & Pobreza & Feingold et al. (2018); X. Wang et al. (2015) \\
\hline & Políticas & Carden \& Armitage (2013); Feingold et al. (2018); Poustie et al. (2015) \\
\hline & Saúde pública & $\begin{array}{l}\text { Carden \& Armitage (2013); Feingold et al. (2018); Makropoulos et al. } \\
\text { (2008) }\end{array}$ \\
\hline & Urbanização & Feingold et al. (2018); Sordo-Ward et al. (2016) \\
\hline \multirow{6}{*}{ Econômica } & Custo Capital & Makropoulos et al. (2008); Poustie et al. (2015) \\
\hline & Custo/Benefício & Yilmaz \& Harmancioglu (2010a, 2010b) \\
\hline & Investimentos & Poustie et al. (2015); Reddy (2010); Shao \& Chen (2013) \\
\hline & Rendimento & Srdjevic et al. (2004); Yilmaz \& Harmancioglu (2010a) \\
\hline & Risco Financeiro & Makropoulos et al. (2008); Srdjevic et al. (2004) \\
\hline & Valor Produção & W. Wang (2016); Yilmaz \& Harmancioglu (2010a, 2010b) \\
\hline \multirow{3}{*}{ Outros } & Confiabilidade & $\begin{array}{l}\text { Makropoulos et al. (2008); Poustie et al. (2015); Srdjevic et al. (2004); } \\
\text { Yilmaz \& Harmancioglu (2010a, 2010b) }\end{array}$ \\
\hline & Resiliência & $\begin{array}{l}\text { Poustie et al. (2015); Srdjevic et al. (2004); Yilmaz \& Harmancioglu } \\
\text { (2010a) }\end{array}$ \\
\hline & Vulnerabilidade & $\begin{array}{l}\text { Poustie et al. (2015); Srdjevic et al. (2004); Yilmaz \& Harmancioglu } \\
\text { (2010a) }\end{array}$ \\
\hline
\end{tabular}

Fonte: Elaborado pelos autores.

A partir das preocupações pertinentes ao PB percebe-se que diversos são os fatores que podem influenciar a AD de uma gestão adequada dos recursos hídricos, com a presença de aspectos direta e indiretamente associados a água. Este levantamento é capaz de guiar o desenvolvimen- 
to de futuras pesquisas ou implementações gerenciais relacionadas ao tema, desde que respeitando o perfil e estratégia de cada instituição.

Outra análise que agrega valor à pesquisa é a identificação de falhas desses Sistemas. Aqui, especificamente, realizou-se uma análise de nível métrico (Figura 7), conforme abordado por Camp e Braet (2016), servindo como advertência e alertando outros profissionais (Camp \& Braet, 2016), com o intuito de que essas métricas sejam desenvolvidas e aplicadas de maneira apropriada em pesquisas futuras, visto que pesquisadores e/ou profissionais terão uma visão geral das ressalvas ao introduzir um SAD voltado a GRH. As métricas analisadas são as encontradas conforme definição de Melnyk et al. (2014), tendo os autores feito uso do termo ou não.

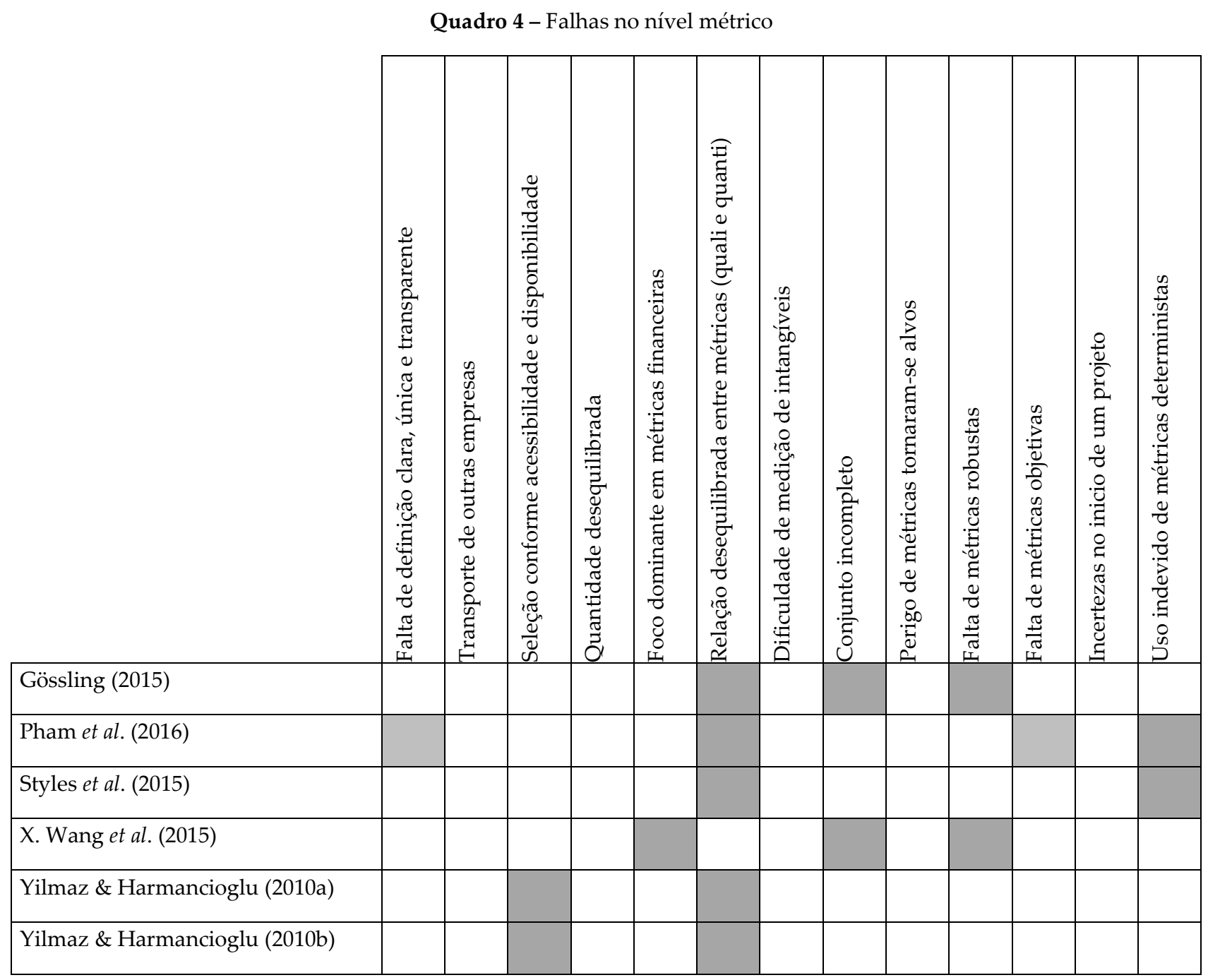

Fonte: Elaborado pelos autores.

A partir dos resultados das falhas apresentados no Quadro 4, percebeu-se que a falha mais presente nesses artigos é a relação desequilibrada entre as métricas, onde os artigos expuseramnas, quase que em sua totalidade, de forma quantitativa. Embora as métricas quantitativas possam exigir cálculos mais avançados levando a resultados mais robustos, o excesso de ênfase nessas métricas pode se tornar sinônimo de uma "supermonetização" (Camp \& Braet, 2016), podendo acarretar um foco dominante de métricas financeiras, outra falha identificada no PB. Uma revisão da natureza de suas métricas deveria ser realizada pelos gestores dos recursos hídricos, visto que o uso equilibrado de métricas quantitativas e qualitativas se faz necessário para um melhor desen- 
volvimento do Sistema, unindo transações financeiras especializadas com análise do comportamento humano (Camp \& Braet, 2016).

Quanto às demais falhas, foram identificadas métricas sem uma definição clara, sendo muito vagas e mal especificadas, influenciando a subjetividade na medição por não descreverem um direcionamento de ações formais que facilitassem a compreensão e aplicabilidade das métricas. Essa falha acaba se relacionando também com a falta de métricas objetivas, também identificada no artigo.

Como a maioria dos artigos apresentou uma estrutura de SAD que condizem com as estratégias propostas em cada caso, conforme visto anteriormente, não houve métricas sendo transportadas de outras empresas ou de outras aplicações. Esse fato confirma a visão do Neely et al. (1995) de que um SAD deve estar alinhado às estratégias da empresa, impossibilitando, assim, uma estrutura única de avaliação para diversas empresas.

Embora fossem formuladas conforme os objetivos de certa bacia hidrográfica, as métricas apresentadas nos artigos de Yilmaz e Harmancioglu (2010a, 2010b) foram desenvolvidas apenas conforme as informações que lhe foram disponibilizadas sobre a bacia, demonstrando uma falha no nível de acessibilidade. Cabe ressaltar que, nos dois artigos dos autores, as medidas e métricas são as mesmas, desenvolvidas para a mesma bacia.

Nos seis artigos com métricas, analisadas no $\mathrm{PB}$, nenhuma excedeu ou se limitou na quantidade de métricas, exibindo cerca de sete a dez métricas em cada artigo, motivo pelo qual também não houve necessidade de dividir as métricas em partes mais tangíveis em nenhum dos artigos.

Sabendo que a complementariedade das métricas é fundamental (Camp \& Braet, 2016), deve-se destacar que um conjunto interligado de métricas careceu em 33,33\% dos artigos, com métricas muito soltas, sem agrupamento adequado que fortalecesse a avaliação.

Por serem falhas interligadas, os mesmos artigos também apresentaram falta de métricas robustas, com apenas um conjunto de métricas disponível. Isso não expõe um resultado adequado para se medir o desempenho, visto que métricas robustas são necessárias para medir o alvo com precisão, por meio da combinação de diferentes parâmetros incorporados em uma estrutura funcional (Camp \& Braet, 2016).

Os artigos de Yilmaz e Harmancioglu (2010a, 2010b) apresentam um exemplo claro de métricas robustas, pois suas métricas são categorizadas em três níveis: métricas ambientais (índice de sustentabilidade agrícola, ambiental e taxa de exploração da água), métricas sociais (confiabilidade da produtividade e déficit da irrigação, confiabilidade da oferta doméstica) e métricas econômicas (relação custo/benefício, eficiência do uso da água de irrigação e valor total da produção).

A última falha identificada em dois dos artigos foi o uso indevido de métricas determinísticas, visto que é desejável introduzir intervalos de confiança ou oferecer uma gama de possíveis soluções ou resultados, a fim de dar uma expressão à incerteza existente (Camp \& Braet, 2016). O perigo de as métricas tornarem-se alvos e incertezas no início de um projeto são falhas não identificadas nos artigos por não ter sido citado nada a respeito pelos autores.

Em termos gerais, os resultados obtidos a partir do desenvolvimento deste estudo revelam que, em práticas de gestão da água, muito ainda deve ser estudado, revisado e aprimorado para garantir uma avaliação adequada do gerenciamento do recurso. A partir disso torna-se possível fazer uso completo dos benefícios que um sistema satisfatório de AD pode promover, alinhando-se as estratégias estabelecidas e contribuindo para a preservação do recurso hídrico. 


\subsection{CONTRIBUIÇÕES PARA O AVANÇO NA ÁREA}

Sabendo que a Avaliação de Desempenho na GRH ainda é um tema emergente, diversas são as oportunidades de pesquisas disponíveis para o progresso do assunto, as quais são propostas pelos autores (Quadro 5) com base nos aportes teóricos discutidos.

Quadro 5 - Oportunidades para os pesquisadores e desafios para os gestores

\begin{tabular}{|c|c|c|}
\hline $\begin{array}{c}\text { Aporte } \\
\text { Teórico }\end{array}$ & Oportunidades para os pesquisadores & Desafios para os gestores \\
\hline $\begin{array}{c}\text { Melnyk } \\
\text { et al. } \\
\mathbf{( 2 0 1 4 )}\end{array}$ & $\begin{array}{c}\text { Fazer um levantamento das medidas mais } \\
\text { utilizadas na GRH para gerar um diagnóstico } \\
\text { do desenvolvimento da área. }\end{array}$ & $\begin{array}{c}\text { Construir métricas de desempenho para propor- } \\
\text { cionar uma avaliação concreta. }\end{array}$ \\
\hline $\begin{array}{c}\text { Neely } \text { et } \\
\text { al. (1995) }\end{array}$ & $\begin{array}{c}\text { Propor ferramentas para identificar medidas } \\
\text { de desempenho para auxiliar no progresso da } \\
\text { GRH. }\end{array}$ & $\begin{array}{c}\text { Rever o alinhamento das medidas com a estraté- } \\
\text { gia da organização, assim como se as estratégias } \\
\text { permanecem de acordo com os objetivos da em- } \\
\text { presa. }\end{array}$ \\
\hline $\begin{array}{c}\text { Neely } \text { et } \\
\text { al. (1995) }\end{array}$ & $\begin{array}{c}\text { Desenvolver um SAD completo para auxiliar } \\
\text { na GRH, de modo a promover a sustentabili- } \\
\text { dade do recurso. }\end{array}$ & $\begin{array}{c}\text { Fornecer informações suficientes para colaborar } \\
\text { com o desenvolvimento do Sistema de modo que } \\
\text { atenda aos objetivos da organização. }\end{array}$ \\
\hline $\begin{array}{c}\text { Neely } \text { et } \\
\text { al. (1995) }\end{array}$ & $\begin{array}{c}\text { Considerar o ambiente interno e o externo da } \\
\text { entidade no SAD e induzir gestores a realizar } \\
\text { uma futura retroalimentação do Sistema para } \\
\text { assegurar o alinhamento. }\end{array}$ & $\begin{array}{c}\text { Proceder periodicamente avaliação para alimen- } \\
\text { tar continuamente o seu SAD com dados internos } \\
\text { e externos à organização. }\end{array}$ \\
\hline $\begin{array}{c}\text { Camp e } \\
\text { Braet } \\
(\mathbf{2 0 1 6 )}\end{array}$ & $\begin{array}{c}\text { Investigar as causas para a ocorrência de tais } \\
\text { falhas em Sistemas de gestão da água. }\end{array}$ & $\begin{array}{c}\text { Corrigir suas possíveis falhas no nível métrico, } \\
\text { revisando-as sempre que necessário. }\end{array}$ \\
\hline $\begin{array}{c}\text { Camp e } \\
\text { Braet } \\
\text { (2016) }\end{array}$ & $\begin{array}{c}\text { Revisar e caracterizar os frameworks existentes } \\
\text { na área, destacando as suas principais falhas. }\end{array}$ & $\begin{array}{c}\text { Elaborar um framework de Avaliação de Desem- } \\
\text { penho que não contenha as falhas apontadas. }\end{array}$ \\
\hline $\begin{array}{c}\text { Camp e } \\
\text { Braet } \\
(\mathbf{2 0 1 6 )}\end{array}$ & $\begin{array}{c}\text { Incorporar estudos específicos do comporta- } \\
\text { mento da gestão sobre os recursos hídricos, } \\
\text { apontando suas falhas. }\end{array}$ & $\begin{array}{c}\text { Desenvolver periodicamente feedback a todos os } \\
\text { envolvidos na organização. }\end{array}$ \\
\hline
\end{tabular}

Fonte: Elaborado pelos autores.

Os preenchimentos dessas lacunas de pesquisas tendem a auxiliar na solidificação do tema no meio acadêmico, assim como incentivar a realização de uma Avaliação de Desempenho da água adequada nas organizações, colaborando para a preservação do recurso.

\section{CONSIDERAÇÕES FINAIS}

A presente pesquisa teve por objetivo mapear, na literatura científica internacional, características dos estudos que avaliem o desempenho para apoiar a gestão de recursos hídricos, de modo a contribuir para sua preservação no âmbito social, econômico e ambiental.

Com base nos 40 artigos selecionados, utilizando-se o instrumento ProKnow- $C$, os quais compõem o Portfólio Bibliográfico, analisaram-se variáveis básicas e avançadas, que proporcionaram a compreensão das características do tema na literatura e, assim, permitiu que os autores pudessem apontar oportunidades de pesquisa para a evolução da área.

Desse modo, os principais resultados apontados pelo estudo são: (i) a existência de um autor de destaque na área, Gordon Huang, assim como uma instituição de destaque em pesquisas sobre o tema, University of Regina; (ii) a área é considerada emergente, com um crescimento significativo de publicações a partir de 2010; (iii) os conceitos distintos de medidas e métrica não são conhecidos pelos pesquisadores da área, comprovando o que já havia sido abordado por Melnyk et al. (2014); (iv) os trabalhos na área que apresentam um SAD, na concepção proposta pelos teóricos 
de AD são escassos; e (v) a existência de falhas no nível métrico está presente nos artigos analisados e a que apresenta destaque é o uso excessivo de métricas quantitativas para avaliar o desempenho.

Após identificar-se o fragmento da literatura que aborda a Avaliação de Desempenho na GRH, percebe-se que fragilidades estão amplamente presentes, desde a conceituação até o desenvolvimento de sistemas robustos. Assim, a caracterização efetuada proporciona um marco para incentivar novas pesquisas sobre o tema, visto que muito ainda deve ser aprimorado e estudado na área para promover uma gestão mais bem capacitada desse recurso que é indispensável para a vida.

No campo prático, a pesquisa buscou evoluir a conscientização entre os gestores das instituições de se realizar práticas adequadas de gerenciamento dos recursos hídricos. Ainda, conhecendo a importância das empresas realizarem uma AD adequada antes de tomar decisões, a presente pesquisa proporciona aos gestores informações que os auxiliem na compreensão de fatores relevantes na construção e controle de um SAD eficaz.

Ademais, os impactos positivos da pesquisa não se limitam ao campo teórico e prático. $\mathrm{O}$ meio ambiente e a sociedade como um todo também tem grande parcela beneficente, pois ao incentivar medidas de preservação deste recurso vital, é imensurável o número de pessoas que podem ser direta ou indiretamente afetadas pelos benefícios desta.

É importante salientar que os resultados apresentados nesta pesquisa são limitados a artigos científicos, que continham as palavras-chave estipuladas pelos autores, em apenas duas bases de dados, a Scopus e a Web of Science, com uma limitação temporal de 2000 até 2018, podendo apresentar resultados distintos se essas restrições forem reduzidas. Esses resultados também são fruto da interpretação dos autores sobre o PB, podendo gerar conclusões adversas às dos autores originais dos artigos.

Por fim, após o conhecimento adquirido na elaboração da presente pesquisa, sugere-se que outros trabalhos façam uma análise mais profunda sobre os artigos que apresentam métricas com enfoque na Teoria da Mensuração e que também sejam desenvolvidos trabalhos com base nas lacunas de pesquisa destacadas na seção 4.3 deste trabalho.

\section{REFERÊNCIAS}

Agência Nacional de Águas (2013). Alternativas organizacionais para gestão de recursos hídricos. Brasília: Mares Design e Comunicação. Recuperado em 10 março, 2018, de http://capacitacao.ana.gov.br/conhecerh/handle/ana/59

Almeida, C. M. V., Borges D., Jr., Bonilla, S. H., \& Giannetti, B. F. (2010). Identifying improvements in water management of bus-washing stations in Brazil. Resources, Conservation and Recycling, 54(11), 821-831.

Biswas, A. K. (2004). Integrated water resources management: a reassessment: a water forum contribution. Water international, 29(2), 248-256.

Bititci, U. S., Garengo, P., Ates, A., \& Nudurupati, S. S. (2014). Value of maturity models in performance measurement. International Journal of Production Research, 53(10), 3062-3085.

Bourne, M., Mills, J., Wilcox, M., Neely, A., \& Platts, K. (2000). Designing, implementing and updating performance measurement systems. International Journal of Operations \& Production Management, 20(7), 754-771. 
Borowski, I., \& Hare, M. (2007). Exploring the gap between water managers and researchers: difficulties of model-based tools to support practical water management. Water Resources Management, 21(7), 1049-1074.

Camp, J. van, \& Braet, J. (2016). Taxonomizing performance measurement systems' failures. International Journal of Productivity and Performance Management, 65(5), 672-693.

Carden, K., \& Armitage, N. P. (2013). Assessing urban water sustainability in South Africa-not just performance measurement. Water $S A, 39(3)$.

Carneiro-da-Cunha, J. A., Hourneaux F., Jr., \& Corrêa, H. L. (2016). Evolution and chronology of the organizational performance measurement field. International Journal of Business Performance Management, 17(2), 223-240.

Choong, K. K. (2014). Has this large number of performance measurement publications contributed to its better understanding? A systematic review for research and applications. International Journal of Production Research, 52(14), 4174-4197.

Dutra, A., Ripoll-Feliu, V. M., Fillol, A. G., Ensslin, S. R., \& Ensslin, L. (2015). The construction of knowledge from the scientific literature about the theme seaport performance evaluation. International Journal of Productivity and Performance Management, 64(2), 243-269.

Elkington, J. (1998). Partnerships from cannibals with forks: The triple bottom line of 21st-century business. Environmental Quality Management, 8(1), 37-51.

Fattahi, P., \& Fayyaz, S. (2010). A compromise programming model to integrated urban water management. Water Resources Management, 24(6), 1211-1227.

Feingold, D., Koop, S., \& Leeuwen, K. van (2018). The City Blueprint Approach: Urban Water Management and Governance in Cities in the US. Environmental Management, 1-15.

Franco-Santos, M., Kennerley, M., Micheli, P., Martinez, V., Mason, S., Marr, B., \& Neely, A. (2007). Towards a definition of a business performance measurement system. International Journal of Operations \& Production Management, 27(8), 784-801.

Furlong, C., Brotchie, R., Considine, R., Finlayson, G., \& Guthrie, L. (2017). Key concepts for integrated urban water management infrastructure planning: lessons from Melbourne. Utilities Policy, 45, 84-96.

Ghalayini, A. M., \& Noble, J. S. (1996). The changing basis of performance measurement. International Journal of Operations \& Production Management, 16(8), 63-80.

Global Water Partnership (2000). Integrated Water Resources Management. TAC Background Papers. Recuperado em 24 setembro, 2018, de https://www.gwp.org/globalassets/global/toolbox/publications/background-papers/04integrated-water-resources-management-2000-english.pdf 
Gössling, S. (2015). New performance indicators for water management in tourism. Tourism Management, 46, 233-244.

Hashemi, H., Bazargan, J., \& Mousavi, S. M. (2013). A compromise ratio method with an application to water resources management: an intuitionistic fuzzy set. Water Resources Management, 27(7), 2029-2051.

Hassanzadeh, E., Elshorbagy, A., Wheater, H., \& Gober, P. (2016). A risk-based framework for water resource management under changing water availability, policy options, and irrigation expansion. Advances in Water Resources, 94, 291-306.

Huang, G. H., \& Loucks, D. P. (2000). An inexact two-stage stochastic programming model for water resources management under uncertainty. Civil Engineering Systems, 17(2), 95-118.

Hubbard, G. (2009). Measuring organizational performance: beyond the triple bottom line. Business strategy and the environment, 18(3), 177-191.

Makropoulos, C. K., Natsis, K., Liu, S., Mittas, K., \& Butler, D. (2008). Decision support for sustainable option selection in integrated urban water management. Environmental Modelling $\mathcal{E}$ Software, 23(12), 1448-1460.

Manzardo, A., Mazzi, A., Loss, A., Butler, M., Williamson, A., \& Scipioni, A. (2016). Lessons learned from the application of different water footprint approaches to compare different food packaging alternatives. Journal of Cleaner Production, 112, 4657-4666.

Marlow, D. R., Moglia, M., Cook, S., \& Beale, D. J. (2013). Towards sustainable urban water management: A critical reassessment. Water Research, 47(20), 7150-7161.

Melnyk, S. A., Bititci, U., Platts, K., Tobias, J., \& Andersen, B. (2014). Is performance measurement and management fit for the future? Management Accounting Research, 25(2), 173-186.

Neely, A. (1999). The performance measurement revolution: why now and what next? International Journal of Operations \& Production Management, 19(2), 205-228.

Neely, A., Gregory, M., \& Platts, K. (1995). Performance measurement system design: a literature review and research agenda. International Journal of Operations \& Production Management, 15(4), 80-116.

Pham, T. T., Mai, T. D., Pham, T. D., Hoang, M. T., Nguyen, M. K., \& Pham, T. T. (2016). Industrial water mass balance as a tool for water management in industrial parks. Water Resources and Industry, 13, 14-21.

Poustie, M. S., Deletic, A., Brown, R. R., Wong, T., Haan, F. J. de, \& Skinner, R. (2015). Sustainable urban water futures in developing countries: the centralised, decentralised or hybrid dilemma. Urban Water Journal, 12(7), 543-558.

Reddy, V. R. (2010). Water sector performance under scarcity conditions: a case study of Rajasthan, India. Water Policy, 12(5), 761-778. 
Ren, J. L., Lyu, P. H., Wu, X. M., Ma, F. C., Wang, Z. Z., \& Yang, G. (2013). An informetric profile of water resources management literatures. Water Resources Management, 27(13), 46794696.

Rennings, K., \& Rammer, C. (2011). The impact of regulation-driven environmental innovation on innovation success and firm performance. Industry and Innovation, 18(03), 255-283.

Richardson, R. J. (2014) Pesquisa social, métodos e técnicas. (3a ed.). São Paulo: Atlas.

Rieckermann, J., Daebel, H., Ronteltap, M., \& Bernauer, T. (2006). Assessing the performance of international water management at Lake Titicaca. Aquatic Sciences, 68(4), 502-516.

Shao, L., \& Chen, G. Q. (2013). Water footprint assessment for wastewater treatment: method, indicator, and application. Environmental Science \& Technology, 47(14), 7787-7794.

Sordo-Ward, Á., Granados, I., Martín-Carrasco, F., \& Garrote, L. (2016). Impact of Hydrological Uncertainty on Water Management Decisions. Water Resources Management, 30(14), 55355551.

Srdjevic, B., Medeiros, Y. D. P., \& Faria, A. S. (2004). An objective multi-criteria evaluation of water management scenarios. Water Resources Management, 18(1), 35-54.

Styles, D., Schoenberger, H., \& Galvez-Martos, J. L. (2015). Water management in the European hospitality sector: Best practice, performance benchmarks and improvement potential. Tourism Management, 46, 187-202.

The World Bank (2017). Water Resources Management. Recuperado em 6 maio, 2018, de http://www.worldbank.org/en/topic/waterresourcesmanagement\#1

University of Regina (2018). Water, Environment, and Sustainability - Research Environment. Recuperado em 21 abril, 2018, de https://www.uregina.ca/science/C150RCWaterEnvironmentSustainability-ResearchEnvironment.html

Urich, C., \& Rauch, W. (2014). Exploring critical pathways for urban water management to identify robust strategies under deep uncertainties. Water Research, 66, 374-389.

Thiel, G. G., Ensslin, S. R., \& Ensslin, L. (2017). Street lighting management and performance evaluation: opportunities and challenges. Lex Localis, 15(2), 303-328.

Wang, W. (2016). Establishment of the performance evaluation model of integrated water resources management and empirical study. Revista de la Facultad de Ingeniería, 31(4).

Wang, X., Yang, H., Shi, M., Zhou, D., \& Zhang, Z. (2015). Managing stakeholders' conflicts for water reallocation from agriculture to industry in the Heihe River Basin in Northwest China. Science of the Total Environment, 505, 823-832. 
Wessman, H., Salmi, O., Kohl, J., Kinnunen, P., Saarivuori, E., \& Mroueh, U. M. (2014). Water and society: mutual challenges for eco-efficient and socially acceptable mining in Finland. Journal of Cleaner Production, 84, 289-298.

Yilmaz, B., \& Harmancioglu, N. B. (2010a). An indicator based assessment for water resources management in Gediz River Basin, Turkey. Water Resources Management, 24(15), 4359-4379.

Yilmaz, B., \& Harmancioglu, N. B. (2010b). Multi-criteria decision making for water resource management: a case study of the Gediz River Basin, Turkey. Water SA, 36(5). 